\title{
Application of electrical resistivity tomography for the study of the continental shelf and coast in northern Peru for a foundation of a harbor
}

Christ Jesus Barriga Paria, Jorge Pantaleón Barriga Gamarra and Eleonardo Lucas Pereira

Copyright 2019, SBGf - Sociedade Brasileira de Geofísica

This paper was prepared for presentation during the $16^{\text {th }}$ International Congress of the Brazilian Geophysical Society held in Rio de Janeiro, Brazil, 19-22 August 2019.

Contents of this paper were reviewed by the Technical Committee of the $16^{\text {th }}$ International Congress of the Brazilian Geophysical Society and do not necessarily represent any position of the SBGf, its officers or members. Electronic reproduction or storage of any part of this paper for commercial purposes without the written consent of the Brazilian Geophysical Society is prohibited.

\section{Abstract}

The harbor located in the Peruvian northern region will be one of the most important of the sector, which will have a non-linear structure built with blocks of considerable dimensions, placed in the water and on the sea coast, with the intention of increasing the flow in several directions defined, guaranteeing the reduction of the waves, improve the fishing activity and avoid the settling of sand. The investigation provided the first contributions to the marine geophysical exploration of the continental and coastal platform of that extension with the vision of applications to the civil engineering for foundations. Using an integrated approach to study this area in order to obtain a detailed, systematic, geological-geophysical survey of the continental shelf and littoral, it was proposed to achieve a detailed stratigraphy and determine possible anomalies. The investigation included the study of electrical resistivity tomography (ERT) with a configuration and array of pole-dipole electrodes, being made two on the continent and two at sea, and electrical resistivity tomography (EST) by the Schlumberge method, three on the continent and two in the sea. The most surprising results were the materials found in the strata and the discovery of a pit whose dimensions were found in the range of 22 to $13 \mathrm{~m}$ in thickness, being completely filled with fine sediments. It is interesting to observe that the geo-electric resistivity anomaly found will have the purpose of supporting the necessary measures to be carried out in the foundation of the harbor, which reaffirms that the application of geophysics is an essential tool.

\section{Introduction}

At present, there are various methods of geophysical survey that can be used at sea or in the air. The higher capital and operating costs associated with maritime or air work are offset by the greater speed of operation and the benefit of being able to inspect areas where the terrain is difficult to access or even impossible (Kearey et al, 2002). The location of the vessel is determined directly with sources and receivers that are determined in relation to the vessel, precise positioning, direction of the vessel is required to obtain the data where necessary, it also requires a precise positioning and direction of the vessel to avoid dangers marine navigation is based on the observation of radio waves or GPS to determine the position of the vessel in relation to known reference positions with precision known as "base stations" (Gadallah et Fisher, 2009).

\section{Method}

Pole-dipole Sounding

According to Keller et Frischknecht (1966), the poledipole array has been widely used in electric road surveys oriented to the exploration of groundwater and mining. This happens depending on some of its positive characteristics, such as the operational ease in the field and its symmetry that is peculiar to it. The configuration and distribution of electrodes used according to the poledipole method in fieldwork are shown in Fig. 1.

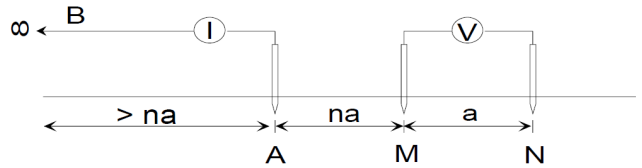

Figure 1 - Pole-dipole configuration

The measurements allowed registering the variations of lateral and vertical resistivity of the subsoil, to present them in the 2D model, which allows constructing graphically what is called a "pseudo" as seen in Fig. 2 . That is, it seeks to increase the number of field measurements, that commonly occur in the form of pseudo-sections of apparent resistivity. The density of the data is very important for the resolution capacity, especially for narrow structures (Dahlin et Loke, 1998).

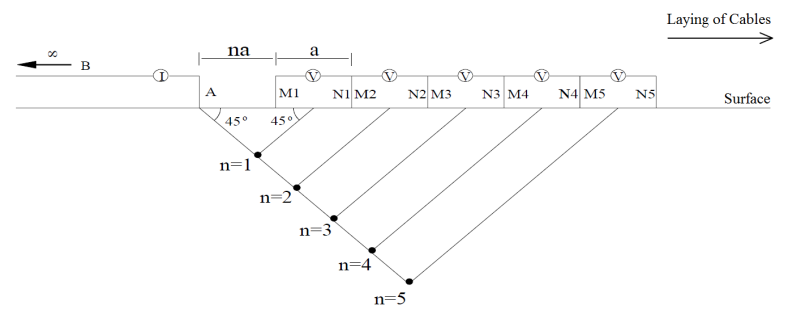

Figure 2 - Representation of pseudosections through the polo-dipole technique

Field surveys

According to Borges (2007), the computational tool allows a greater capacity of calculations and the obtaining of images of the real distribution of the subsoil. For the 
present investigation, the measurements were made with the following spacing of current electrodes in continent $A B / 2$ are indicated in each figure, while for the internal electrodes $\mathrm{MN} / 2$ or potential were $0.25,0.75,2.5$ and 7.5 meters respectively. The EST-01, EST-02 and EST-03 tomographies were performed on the seashore, which was found on saturated to wet areas, and EST-04 and EST-05 offshore, measurements of resistivity taken from a ship fixed with 2 anchors, as shown in Fig. 3. The resulting plot of plotting in logarithmic coordinates, the resistivities in the ordinates and the electrode spacing in the abscissa, is the curve called EST (Electrical Point Tomography), like the one attached in the annex corresponding, are shown in Fig. 4.

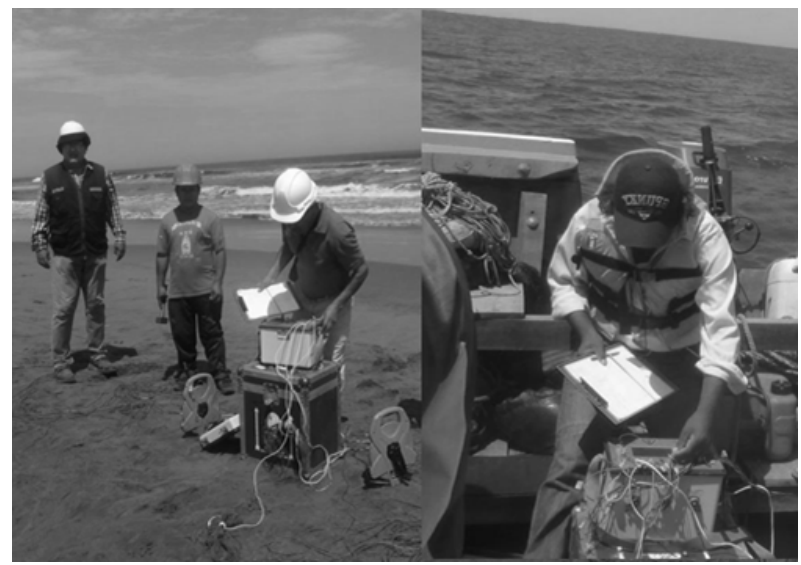

Figure 3 - Geophysical prospection by electrical tomography (right side continental prospecting, left side marine survey)

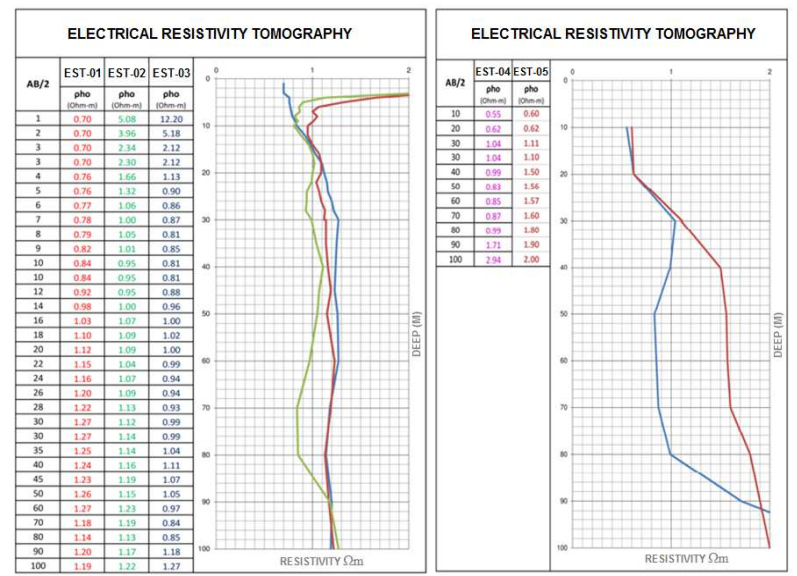

Figure 4 - Plotting the data of the electrical tomographies performed (right side plotting continental prospecting, left side plotting marine survey)

\section{Desktop work}

This phase of the study was carried out in a qualitative way to then quantify the resistive and thickness values of each anomaly or changes in trends in the direction of the curve; These values of thicknesses have allowed generating Fig. 5 and 6, in turn, which must be interpreted as geo-resistivity. For the interpretation of the data obtained from the prospection the existence of some questions, among which are the principle of equivalence, the suppression of strata and anisotropy (Orellana, 1972).

Results of electrical resistivity tomography - Schlumberge Method

This phase of the study will include correlating the resistivities found with the point electrical tomographies (equivalent to a VES with measures of detail resistivity, in order to differentiate small variations in resistivity or thickness of low power strata), which are represented in a column lithological for each of the EST, then the columns will be integrated to represent them in a geo-electric resistivity section, thus having in $2 \mathrm{D}$ the stratigraphy of the investigated areas.

\section{Continental electrical resistivity tomography}

The EST-01 is arranged under a built-in jetty, where the sands are saturated by the effect of the waves. The EST02 is located 100 meters north of the already built jetty, where the sands are at a low saturation level. The EST03 located 100 meters south side of the built breakwater, where the sands are moderately saturated. Table 1 shows the geological specifications found and Fig. 7 shows the geo-electric resistivity columns of the surveys carried out.

\section{Results}

The EST-01 is arranged under a built-in jetty, where the sands are saturated by the effect of the waves. The EST02 is located 100 meters north of the already built jetty, where the sands are at a low saturation level. The EST03 located 100 meters south side of the built breakwater, where the sands are moderately saturated. Fig. 5 shows the geo-electric resistivity columns of the surveys carried out.

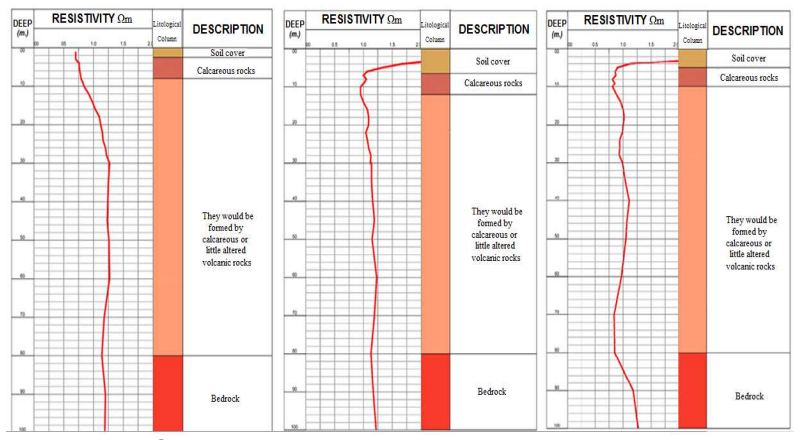

Figure 5 - Stratigraphic columns made in continent

\section{Marine electrical resistivity tomographies}

The EST-04 located on the progressive $0+1000 \mathrm{~m}$ of the spring axis and the EST-05 located on the progressive 0 $+900 \mathrm{~m}$ also on the spring axis. Fig. 6 shows the geoelectric resistivity columns of the explorations carried out. 


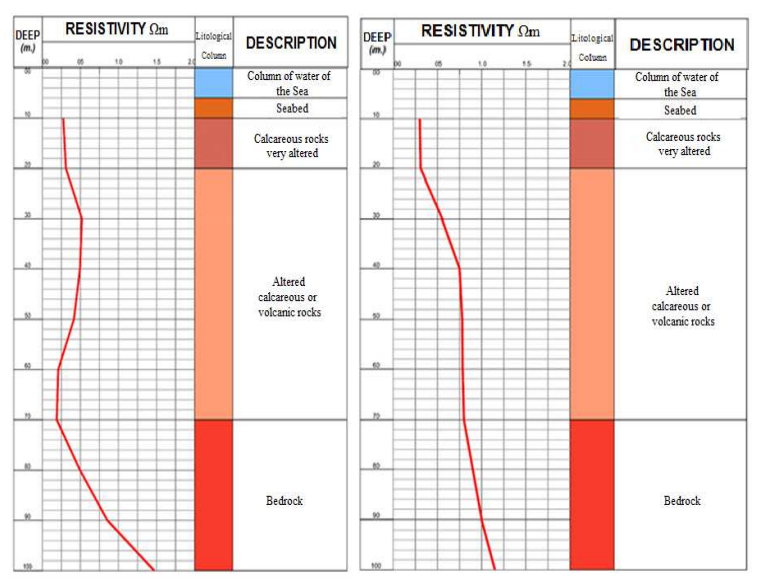

Figure 6 - Stratigraphic columns made in the sea

\section{Geoelectrical sections}

The results of the geo-electric resistivity columns were correlated with each other, with the purpose of being able to observe in 2D the characteristics of the geo-electric resistivity layers described previously that are the geoelectric resistivity section A-A 'and B-B'.

\section{Geoelectrical Section A-A'}

This geoelectrical section has been drawn by joining the three point tomographies carried out on the seashore. The stratification is very parallel to each other, indicating a calm superficial geological formation, that is to say, no geological structures or faults are differentiated in the 280 linear meters investigated, it is shown in Fig. 7.

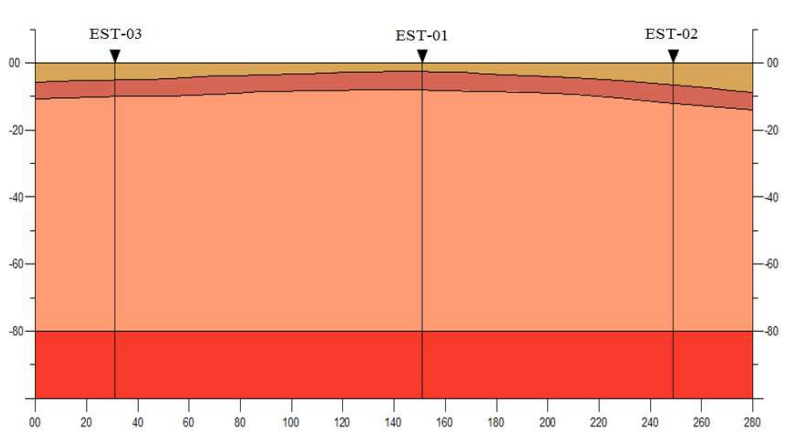

Figure 7 - Geoelectrical Section A-A' drawn by joining the points of the EST-01, EST-02 and EST-03 located on the seafront

\section{Geoelectrical Section B-B'}

This geoelectrical section has been drawn by joining the three point tomographies made in the sea, as shown in Fig. 1. The stratification is very parallel to each other, which indicates an undisturbed superficial geological formation, that is to say, no differentiation of structures or
Geological faults in the 650 linear meters investigated is shown in Fig. 8.

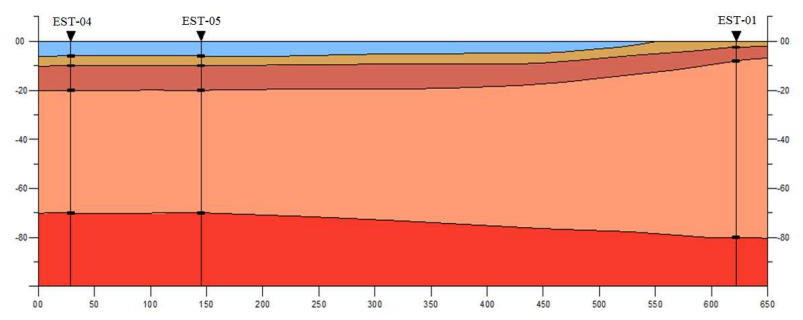

Figure 8 - Geoelectrical Section B-B' drawn connecting the points of the EST-04 and EST-05 and EST-01 located in the sea with a thickness of 6 meters of water mattress

\section{Results of electrical tomography}

First tomographic line ERT-01

It is located under the jetty pier, lying parallel to the coast of the sea with coordinates and is represented in Fig. 10, where the stratigraphic sequence is observed where the first stratum (shades of green), corresponding to the ground covered by mobile sands by the action of the waves of the sea, with a thickness that varies from 3 to 6 meters, their resistivities vary from 0.5 to $2 \Omega-\mathrm{m}$. These characteristics extend until 27 to 30 meters of depth, for this reason to a greater depth of 6 meters they would correspond to altered calcareous rocks and filled with saturated clays of salty water. The second stratum (celestial to blue), shows some resistivities of 0.02 to 0.4 $\Omega-m$, would correspond to bags of salt water, distributed as shown in Fig. 12, the possibility of corresponding to highly altered and filled calcareous rocks is not ruled out with clays saturated with salt water. The third stratum (yellow to brown and red) the distribution of this stratum is also punctual, for this reason, they are described as altered calcareous rocks in the superficial part and towards the central part healthy, they are presented with thicknesses of 7 to 26 meters. The last layer (red to purple) is homogeneously distributed more than 30 meters deep; correspond to the rocky substrate or healthy rocks.

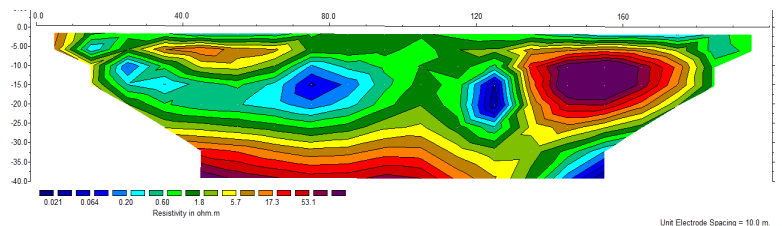

Figure 10 - Tomographic line ERT- 01located below the Jetty of the harbor

Second tomographic line ERT-02

This tomographic line has been made below the pier constructed jetty, that is, orthogonal to the marine coast, the tomography is shown in Fig. 11. It is significant to indicate that the end of the ERT was placed at the end of 
the jetty built in water, observed the stratigraphic sequence where the first stratum (shades of green), would correspond to the cover soil formed by moving sands by the action of the waves of the sea, with thickness that varies from 1 or 2 to 8 meters, their resistivities vary from 0.5 to $2 \Omega-\mathrm{m}$. These characteristics extend until 5 to 25 meters of depth, for this reason at a greater depth of 2 to 8 meters correspond to altered calcareous rocks and filled with saturated clays of salt water. The second stratum (celestial to blue) with resistivities of 0.02 to $0.4 \Omega-\mathrm{m}$, would correspond to bags of salt water, in Fig. 13 they are very isolated 170 to 180 $\mathrm{m}$. For the purposes of the present study, it has no greater impact. The third stratum (yellow, brown and orange) shows a distribution of this stratum is very regular and somewhat parallel to the surface topography, correspond to calcareous rocks with thicknesses of 7 to more than 30 meters thick of the progressive 120 at the end of the ERT the fourth layer (red to purple) is established similar to the previous stratum 22 located more than 50 meters deep from the progressive 120 at the end of the ERT correspond to the rocky substrate.

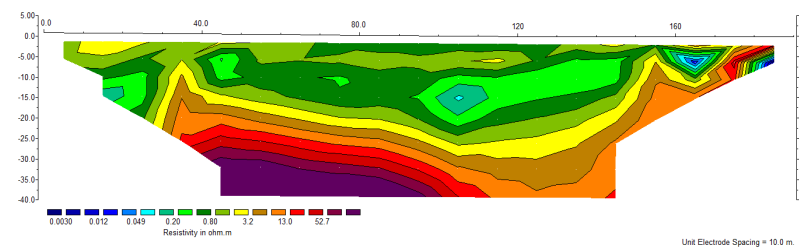

Figure 11 - Tomographic line ERT-02 located below the jetty of the harbor

\section{Third tomographic line ERT-03}

This tomographic line has been made to 1000 meters of progressive that has the jetty of the harbor, and is in the sea with 6 meters of water mattress, as shown in plant the Fig. 12, this ERT-03 the stratigraphic sequence is observed where the first stratum (blue to blue) with resistivities of 0.02 to $0.4 \Omega-\mathrm{m}$ would correspond to the seawater mattress on which the ERT-03 was made. The graphics show a constant thickness of 7 to 9 meters between the progressive 00 to 82 meters, where the thickness is increased to 22 meters. We interpret as a small pit that they would be full of fine sediments with fine saturated sands; this appreciation would explain the presence of the green lens (sediments of greater compaction) located between the 100 to $172 \mathrm{~m}$ increments, with a thickness of 3 to 4 meters, for the objectives of this project, it is worth verifying this geological form. The second stratum (shades of green) would be made up of fine sands and clays saturated with resistivities of 0.5 to $2 \Omega-\mathrm{m}$, its thickness varying from 6 to 7 meters, is located 7 to 9 meters deep from the surface of the sea located between the progressive 00 to 82 meters, where the thickness increases to 22 meters and decreases to 12 meters towards the end of the ERT. The third stratum (yellow, brown and orange) shows a distribution of this stratum is similar to the previous stratum, which extends throughout the tomographic section, with a thickness from 7 to more than 20 meters thick. The last stratum (red) is located similar to the previous stratum, it is 33 to more than 60 meters deep. Lithologically they correspond to the rocky substratum.

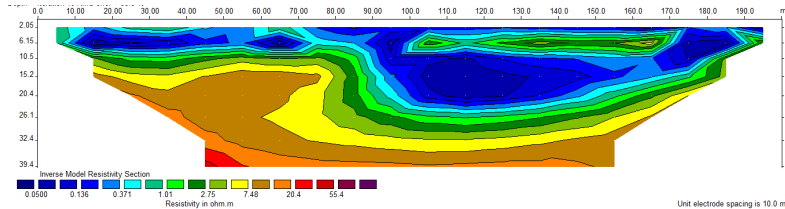

Figure 12 - Tomographic line ERT-03 is located 600 meters from the coast at sea

\section{Fourth tomographic line ERT-04}

This tomographic line has been made to 1000 meters of progressive that has the jetty of the harbor, and is in the sea with 6 meters of water mattress, as shown in plant the Fig. 13 plant, this ERT-04 the stratigraphic sequence is observed where the first layer (blue to blue) has resistivities of 0.02 to $0.4 \Omega-m$ correspond to the seawater mattress on which the ERT-04 was made. The graphs show a constant thickness of 6 to 16 meters between the progressive 90 at the end of the ERT 82 . Between the progressive 12 to 90 there is a small pit with a thickness of 8 to 15 meters, which would be full of fine sediments with sands saturated fine; This appreciation would explain the presence of the green lens (sediments of greater compaction) located between the progressive 27 to $75 \mathrm{~m}$. with a thickness of 3 to 7 meters. For the purposes of this project, it is worth verifying this geological form. The second stratum (shades of green) would be made up of fine sands and clays saturated with resistivities of 0.5 to 2 $\Omega-m$, its thickness varying from 6 to 7 meters, is located 7 to 9 meters deep from the surface of the sea located between the progressive 00 to 82 meters, where the thickness increases to 22 meters and decreases to 12 meters towards the end of the ERT. The third stratum (yellow, brown and orange) the distribution is similar to the previous stratum, which extends throughout the tomographic section, with a thickness from 7 to more than 20 meters thick. The fourth layer (red to purple) is located similar to the previous stratum, it is 33 to more than 60 meters deep and lithologically correspond to the rocky substrate.

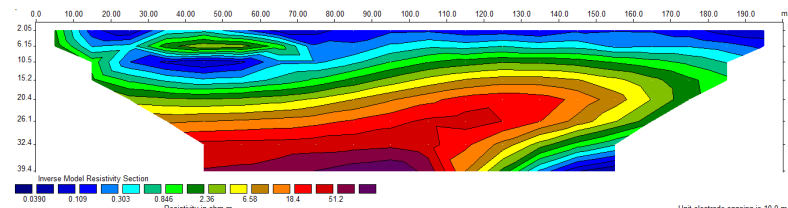

Figure 13 - Tomographic line ERT-03 is located 600 meters from the coast at sea 


\section{Conclusions}

Sounding using electrical tomography proved to be a friendly tool for obtaining relevant data at sea, although it is recognized that the efforts made were greater than those of a seismic survey, in addition to the presence of "marine effects" revealed to be a variable of which should be prudent to avoid arbitrarily applying any orientation of such effects. Another variable to consider should be the local topography of the continental shelf to verify its influence during minor prospections, the predefined geometry of the area will help to obtain better values.

The study area has been investigated with 5 electrical tomographies by the Schlumberge method distributed in such a way that perfectly cover the proposed objectives, 3 EST are on the seashore and the last 2 to approximately on the progressive 1000 of the jetty of the pier. The continent ESTs were performed with spacing of $A B / 2$ electrodes of $1 \mathrm{~m}$ in the first 10 meters, $2 \mathrm{~m}$ of 10 to 30 meters, $5 \mathrm{~m}$ of 30 to 50 meters and $10 \mathrm{~m}$ of 50 to 100 meters, that way had greater resolution in the first 30 meters of depth, which could differentiate strata up to a meter thick. The EST carried out at sea were carried out with a constant spacing of 10 meters, taking advantage of the ERT cables, the results of both studied zones are presented in Fig. 4, 5 and 6.

Electrical tomographies were also performed with the configuration of Polo-Dipole electric electrodes. To have continuous information, both vertical and horizontal, along with the extended lines. It has been carried out two in the continent and two in the sea, finding a geology of sand and clay class granulometries, including the depths to which these are located.

The main characteristics found are with the ERT-03 located in the progressive 1000 of the jetty of the harbor, a small pit has been found between the progressive ones of 82 at the end of the tomography, with thicknesses ranging from 22 to $13 \mathrm{~m}$. that they would be full of fine sediments with fine saturated sands; This assessment would explain the presence of a lenticular layer with a thickness of 3 to 4 meters, formed by sediments of greater compaction located between the 100 to $172 \mathrm{~m}$ increments. For the purposes of this project, it is worth checking this geological form. Similar geo-electric resistivity anomaly has also differentiated with the ERT; in this case, the small sedimentary pit is smaller.

\section{References}

Borges, W. R. 2007. Caracterização geofísica de alvos rasos com aplicações no planejamento urbano e meio ambiente: estudo sobre o sitio controlado do IAG/USP. Tese de Doutorado, Instituto de astronomia, geofísica e ciências atmosféricas, IAGUSP, 256p.

Dahlin, T. \& Loke, M. H. 1998. Resolution of 2D Wenner resistivity imaging as assessed by numerical modelling, Journal of Applied Geophysics, 38: 237-249.

Gadallah M. R. and Fisher R., Exploration Geophysic An Introduction Springer-Verlag Berlin Heidelberg 2009, 257 p.
Kearey P., Brooks M. and Hill I., An Introduction to Geophysical Exploration 2002, Blackwell Science, third edtion, $257 \mathrm{p}$.

Keller, G. V. \& Frischknecht, F. C. 1966. Electrical methods in geophysical prospecting. Oxford: Pergamon Press. 517 pp.

Orellana, E. Prospección geoeléctrica en corriente continua. Ed. Paraninfo, 1972. 